\title{
Thermomechanical Behavior of Energy Pile Embedded in Sandy Soil
}

\author{
Xu Huang $\mathbb{D}^{1},{ }^{1}$ Yajun Wu $\mathbb{D}^{\mathbb{D}},{ }^{1,2}$ Huaifeng Peng, ${ }^{1}$ Yaohu Hao, ${ }^{1}$ and Chenyang $\mathrm{Lu}^{2}$ \\ ${ }^{1}$ Key Laboratory of Ministry of Education for Geomechanics and Embankment Engineering, Hohai University, Nanjing 210098, China \\ ${ }^{2}$ Department of Civil Engineering, Shanghai University, Shanghai 200072, China \\ Correspondence should be addressed to Yajun Wu; wyjdldz@163.com
}

Received 21 May 2017; Revised 14 July 2017; Accepted 31 July 2017; Published 7 March 2018

Academic Editor: Marco Pizzarelli

Copyright (c) $2018 \mathrm{Xu}$ Huang et al. This is an open access article distributed under the Creative Commons Attribution License, which permits unrestricted use, distribution, and reproduction in any medium, provided the original work is properly cited.

\begin{abstract}
The traditional energy pile (solid energy pile) has been implemented for decades. However, the design of different kinds of energy piles is still not well understood. In this study, a series of model tests were performed on an aluminum pipe energy pile (PEP) in dry sandy soil to investigate the thermal effects on the mechanical behaviors of pipe energy pile. The thermal responses of the PEP were also analyzed. Steady temperatures of the PEP under different working conditions were also compared with that of the solid energy pile. Different loading tests were carried out on four pipe energy piles under three different temperatures of 5,35 , and $50^{\circ} \mathrm{C}$, respectively. The bearing capacity change can be interpreted through the load-displacement curves. Experiment results were also compared with the solid energy pile to evaluate bearing capacities of the PEP and the solid energy pile under different temperature conditions. The mobilized shaft resistance was also calculated and compared with the solid energy pile data and the results show that the PEP has a similar load transfer mechanism with the solid energy pile. It could also be found that, for PEPs under working load, plastic displacement would appear after a whole heating cycle.
\end{abstract}

\section{Introduction}

Environment pollution due to the use of natural energy resources has been a crucial issue. The ground-source heat exchange system (GSHE) is one of the new techniques that has been applied by civil engineering researchers to reduce the energy demand in heating and cooling systems [1]. However, the additional cost of drilling boreholes for the GSHEs prevents their development [2].

Energy pile system is a new geotechnical technique which was developed to overcome the disadvantage of GSHEs. Energy piles typically include closed-loop tubes in concrete pile foundations, making the pile act not only as load-bearing elements, but also as heat exchange elements. The circulation of fluid (usually water) in heat exchangers allows the energy pile to exchange heat and energy with the ground since the temperature below $4 \mathrm{~m}$ depth underground remains constant [3]. However, the temperature change of pile foundations during heating and cooling may lead to some irreversible volumetric strain for the surrounding soils $[4,5]$. It would also cause the changes in the toe resistance and shaft friction along the pile, which would affect the serviceability and stability of pile foundations [6-8].

Field tests have been conducted to investigate the thermomechanical responses of energy piles. Laloui et al. $[9,10]$ conducted a single pile test at the Swiss Federal Institute of Technology in Lausanne, Switzerland. The $25.8 \mathrm{~m}$ long single concrete pile with a diameter of $0.88 \mathrm{~m}$ was located at the edge of a four-storey building. Optical fiber sensors and extensometers were installed in the concrete pile, as well as a load cell on the base of the pile. A heating and recover cycle was applied to the pile before the construction and after the constructions of each floor (load increased from $0 \mathrm{kN}$ to $1300 \mathrm{kN}$ ). The results show that heating would lead to an increment in axial load, which is larger than that on the pile head load, and the thermal effect was observed more obviously in the pile toe. Bourne-Webb et al. also conducted tests [11] at Lambeth College, London, using a $23 \mathrm{~m}$ long concrete pile with a diameter of $0.55 \mathrm{~m}$. A sustained loadcyclic thermal test was applied on the pile at a working load of $1200 \mathrm{kN}$. The results revealed that the axial load distribution 
TABLE 1: Experimental program of the model tests.

\begin{tabular}{|c|c|c|c|c|c|}
\hline Number & Model pile & Loading condition & Thermal condition $\left({ }^{\circ} \mathrm{C}\right)$ & Test Model & Velocity of water $(\mathrm{L} / \mathrm{min})$ \\
\hline (1) & RPEP & Until failure & Room temperature & $\mathrm{L}$ & - \\
\hline (2) & PEP1 & Until failure & 35 & $\mathrm{H} \rightarrow \mathrm{L}$ & - \\
\hline (3) & PEP2 & Until failure & 50 & $\mathrm{H} \rightarrow \mathrm{L}$ & - \\
\hline (4) & PEP3 & Until failure & 5 & $\mathrm{H} \rightarrow \mathrm{L}$ & - \\
\hline (5) & PEP1 & - & 50 & $\mathrm{H}$ & 5 \\
\hline (6) & PEP1 & - & 50 & $\mathrm{H}$ & 15 \\
\hline (7) & PEP2 & - & 35 & $\mathrm{H}$ & 5 \\
\hline (8) & PEP2 & - & 35 & $\mathrm{H}$ & 15 \\
\hline (9) & PEP3 & - & 5 & $\mathrm{C}$ & 5 \\
\hline$(10)$ & RPEP & working load & 35 & L-H-R-C-R & 5 \\
\hline
\end{tabular}

on the pile depended on the restraint conditions of pile ends. Murphy et al. [12, 13] also conducted tests on fullscale energy foundations to study the thermal axial stress and the displacement. The seasonal thermal responses of energy foundations were also analyzed during the operation period.

Based on the field tests, Amatya et al. [14] conducted further investigation on the effect of end restraints on the mechanical behaviors. Assuming that the pile was embedded in a nonconsolidating ground and the shaft resistance was uniform along the pile, the simplified load transfer mechanisms was explicated.

McCartney and Rosenberg $[15,16]$ and Murphy et al. [17] performed a series of centrifuge tests to investigate the ultimate pile capacities and thermal effects on the shaft resistance of energy foundations. It is proved that the pile capacities would increase with the increasing temperature, which may be the result of the increase in side shear resistance due to the radial expansion of foundation. Stewart and McCartney [18] carried out a centrifuge test to investigate the thermomechanical behaviors of end-bearing energy pile under cyclic heating. The maximum thermal axial stress was observed near the toe of foundation since the bottom part was fully constrained by the model container. Moreover, Goode et al. [19] conducted further centrifuge tests to study the effects of head and end restraints on energy foundations.

$\mathrm{Ng}$ et al. [7] carried out centrifuge tests in the saturated sandy soil to investigate the thermal effects on single pile capacity as well as settlement patterns. Load tests were carried out on four aluminum model piles under different temperature conditions and loading sequences. The neutral plane was observed to shift towards the pile toe during heating. The pile capacities increase by $13 \%$ with a temperature increment of $15^{\circ} \mathrm{C}$, which was mainly attributed to the increase in ultimate shaft resistance. On the other hand, the mobilized toe resistance takes most of the applied axial load with the temperature increment of $30^{\circ} \mathrm{C}$.

Different types of piles are widely used nowadays; however, understanding on these different types of energy piles is still limited. Particularly, the thermal effects on the bearing capacity and effects of different operation model on the thermomechanical behavior of the energy pile have not been fully revealed. In this study, load tests were carried out on four aluminum pipe piles in typical sandy soil. This study aims to investigate the thermal effects on the bearing capacity and load-displacement pattern of the pipe energy pile. In addition, the load transfer mechanism was also investigated. Considering that the material of the model pile is different with the concrete and some boundary effects exist in this study, all the results can only be applied for the model piles and could not be used in the design of energy pile in situ directly.

\section{Experimental Program}

All the tests were performed in four $1 / 20$-scaled model containers with size of $750 \mathrm{~mm} \times 750 \mathrm{~mm} \times 1200 \mathrm{~mm}$ (length $\times$ width $\times$ height). Pipe energy piles in saturated sandy soil with different temperatures, different velocities of fluid in heat exchangers, and different loading sequences were investigated. The test program is summarized in Table 1. Firstly, a load test was carried out on the reference pipe energy pile (RPEP) under the ambient temperature of $15^{\circ} \mathrm{C}$. Since only the mechanical loading was applied to the RPEP, the loading sequence can be denoted as "L." In Tests 2 to 4 (as shown in Table 1), other pipe energy piles (PEP1, PEP2, and PEP3) were heated up or cooled down to temperatures of 35,50 , and $5^{\circ} \mathrm{C}$, respectively (the heating period denoted as " $\mathrm{H}$ " and cooling period as "C"). After that, load tests were conducted (the whole process is denoted as " $\mathrm{H} \rightarrow \mathrm{L}$ "). Thermal responses of piles were investigated in Tests 5 to 6 (heating period denoted as " $H$ "). And working load was applied on the RPEP in Test 7 with a whole cycle (the RPEP was first heated to $35^{\circ} \mathrm{C}$, then recovering to ambient temperature; cooling to $5^{\circ} \mathrm{C}$ after recovering; and finally recovering to ambient temperature; the recovering period could be denoted as " $R$ "). All these tests were conducted in separated model containers and all four piles recovered to the ambient temperature before a new test started.

\section{Soil Properties and Model Preparation}

All the tests were carried out in the saturated sandy soils. The natural dry density and maximum and minimum dry densities are $1.55,1.74$, and $1.47 \times 10^{3} \mathrm{~kg} / \mathrm{m}^{3}$, respectively. The relative density is 0.8 for the tests. The uniformity coefficient and curvature coefficient are 3.0 and 0.9 , respectively. The sandy soil has a mean diameter of $D_{50}=0.34 \mathrm{~mm}$, and the ratio of 

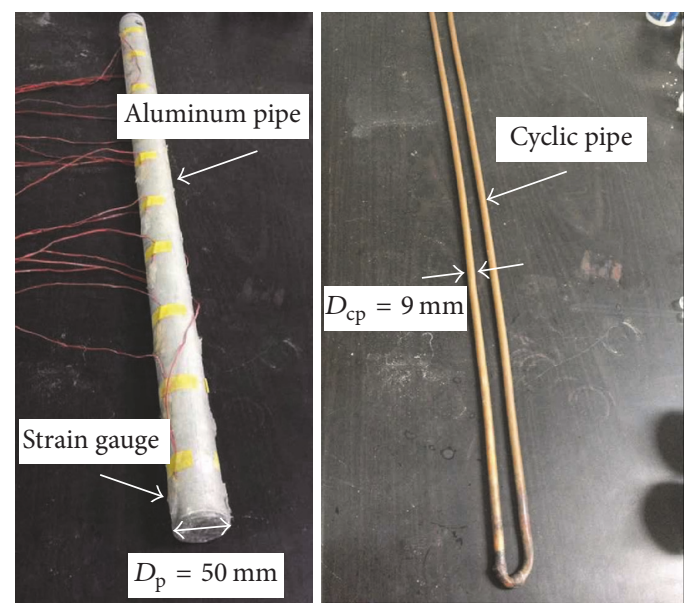

(a)

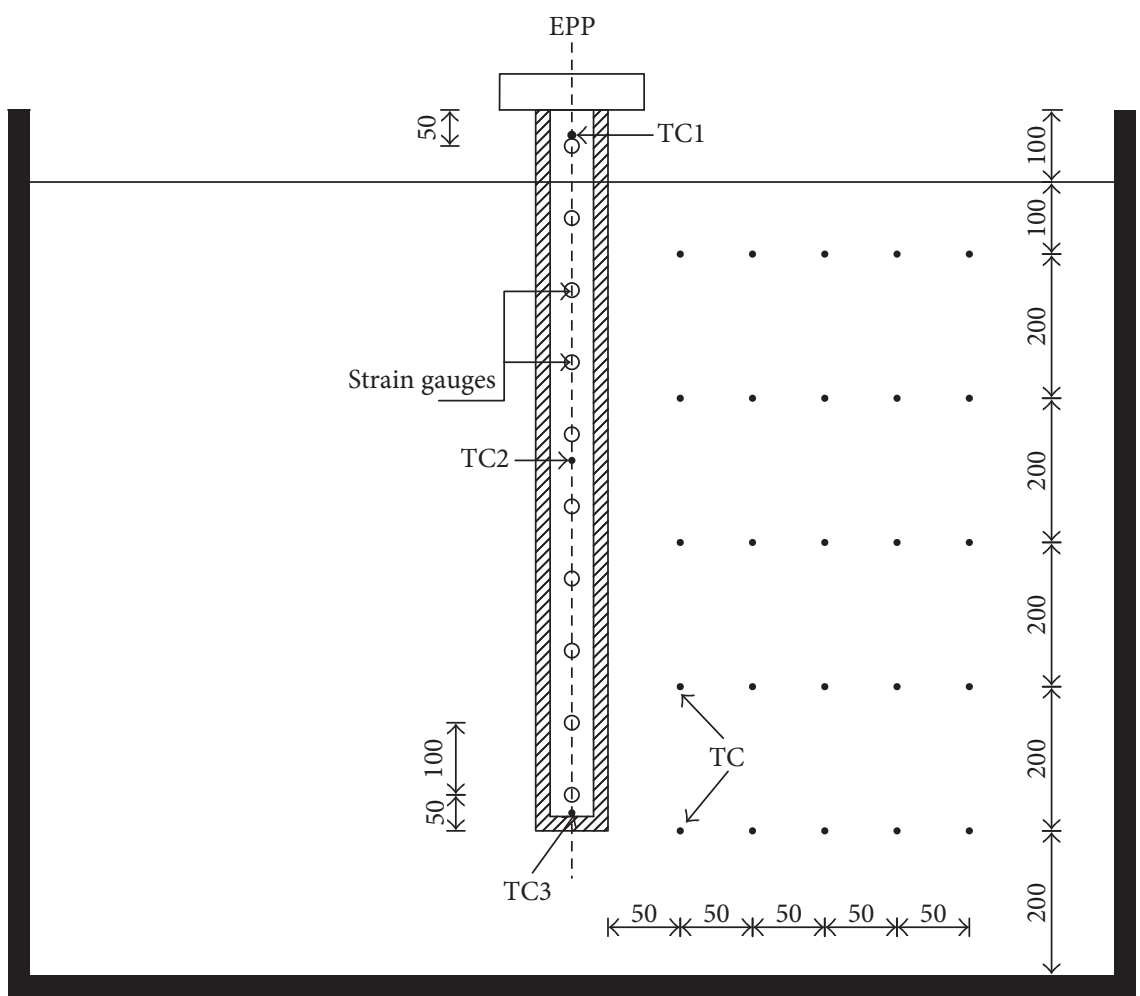

- Thermocouple (TC)

o Strain gauges

(b)

FIGURE 1: Details of model pile and pile instrumentation.

pile diameter to mean particle size $\left(D / D_{50}=147\right)$ is larger than the limiting value recommended by Fioravante [20], so the particle-size scaling effect could be negligible. Direct shear tests were conducted for the pile-soil interface. In the saturated sandy soil, the pile-soil interface angles range from $30.6^{\circ}$ to $31.9^{\circ}$ within the temperature range from 20 to $35^{\circ} \mathrm{C}$.

Figure 1 shows the diagram of containers for the tests. The sandy soil was placed into the containers by tamping. The soil needed was calculated based on the size of model containers and divided into 20 layers to be rained and tamped to ensure the relative compaction in each of the containers to be the same.

\section{Pile Properties and Instrumentation}

The model energy piles were prefabricated from aluminum alloy tubes with Young's modulus of $70 \mathrm{GPa}$. The tube has an inner diameter and outer diameter of $40 \mathrm{~mm}$ and $50 \mathrm{~mm}$, 
respectively. The aluminum pipe energy pile has a thermal expansion coefficient and thermal conductivity of $23 \times$ $10^{-6} \mathrm{~m} /(\mathrm{m} \cdot \mathrm{K})$ and $237 \mathrm{~W} /(\mathrm{m} \cdot \mathrm{K})$, respectively. The thermal expansion of the model energy pile is almost three times than that of a concrete pile $\left(8.6 \times 10^{-6} \mathrm{~m} /(\mathrm{m} \cdot \mathrm{K})\right)$. As a result, the thermal expansion of the model pile and the thermally induced changes in the pile-soil interaction are overestimated in the model tests. The length of model energy pile is $1000 \mathrm{~mm}$, and only $900 \mathrm{~mm}$ is embedded in the sand as shown in Figure 1(b). The distance between the pile toe and bottom of the containers is $20 \mathrm{~cm}$ which equals 4 times of the pile diameter and less than 6 times of pile diameter. Thus some boundary effects would influence the results.

A copper pipe with a diameter of $9 \mathrm{~mm}$ was put into the aluminum pile as heat exchangers. The toe of pile was sealed and the cavity of pipe pile was also filled with water to help the heat transfer from the copper pipe to the aluminum pipe (the model energy pile).

Ten sets of strain gauges were installed on the outer surface of the aluminum pile at a distance of $100 \mathrm{~mm}(2 \mathrm{~m}$ in prototype) and an epoxy resin with a thickness of $2 \mathrm{~mm}$ was applied on the surface to protect the gauges from damage and water. It is demonstrated that the effects of the epoxy resin on the side friction could be negligible. Since only a small part of the side surface was covered by the strain gauges, the effects on the shaft friction could be negligible. The wires connected with the strain gauges were also placed just next to the side wall of pile and kept in loose condition so that the effects of the wires could be reduced to the minimum and be negligible. To reduce the temperature effects on the strain gauges, two strain gauges, connected in the form of a halffull-bridge circuit, were bonded to a single polyimide carrier. Prior to installing the pile in the model container, the strain gauges were calibrated under an axial load of $1 \mathrm{kN}$ on the top of the aluminum pile under temperatures of 15,30 , and $50^{\circ} \mathrm{C}$.

Thermocouples were also installed on the inner side of the pile to monitor the temperature changes. Prior to installation, all the thermocouples were calibrated under temperatures ranging from 15 to $50^{\circ} \mathrm{C}$. The epoxy resin with a thickness of $2 \mathrm{~mm}$ was also applied on the surface of thermocouples to protect them from damage and water. Figure 1 show the photograph and schematic plan of the model energy pile.

\section{Experiment Results}

5.1. Temperature Profiles along the Pipe Energy Pile. The temperature distribution has great influences on the mechanical behaviors of energy piles, and the temperature along the pile body would give more details to explain the thermal induced redistributions of stress and strain.

After heating energy piles continuously for 5 hours (4.17 days in prototype) at a constant temperature of $15^{\circ} \mathrm{C}$ without any load on the top of pile, the measured temperature profiles along the pipe energy piles are shown in Figure 2. The temperature differences of readings have been obtained from the three thermocouples along the pile (TC1, TC2, and TC3). At the end of heating, for the PEP1 in Test 5 and Test 6, the maximum temperature along the pile rose up to $47.75^{\circ} \mathrm{C}$ (target temperature of $50^{\circ} \mathrm{C}$ ) from the initial temperature of $22.88^{\circ} \mathrm{C}$ at the top part of the pile, while the temperature at the bottom of PEP2 went up from 23.44 to $38.25^{\circ} \mathrm{C}$. There is a $9.5^{\circ} \mathrm{C}$ difference between the top and bottom of the PEP1. At the same time, for the PEP2, in Test 7 and Test 8 , the maximum temperature along the pipe energy pile rose up to $33.63^{\circ} \mathrm{C}$ (target temperature of $35^{\circ} \mathrm{C}$ ) at the top of the pile, from the initial temperature of $21.44^{\circ} \mathrm{C}$. And a relatively lower temperature was recorded by the TC3. The temperature near bottom part of the PEP2 went up from 21.56 to $29.3^{\circ} \mathrm{C}$. There is a $4.25^{\circ} \mathrm{C}$ difference between the two readings ( $\mathrm{TC} 1$ and $\mathrm{TC} 3$ ) of the PEP2. Normally, the temperature of energy pile under operation conditions does not show obvious change along the depth because of the heat conduction in the working period. However, the duration of tests in this paper was not long enough for that heat conduction.

The temperature changes of the PEP1 were shown in Figure 2(c). Comparing the temperature changes in Test 5 and Test 6 , it could be found that the value of change in Test 6 is relatively higher than change in Test 5. Normally, the water has a lower heat conduction coefficient than the solid materials. However, the fluid has a different heat conduction types with the solid medium. And the velocity of fluid has effects on its heat conduction coefficient. Both of the velocities in these tests are relatively slow and the type of fluid is laminar flow. Since the velocity of water in Test 6 is higher than that in Test 5 , it could be found that the energy pile with higher velocity of water in the cyclic pipe could have higher heat conduction coefficient between water and the pile under the conditions of this study.

Since the temperature of pile still increased a little bit after 5 hours of heating, models were built in software to simulate an extended heating period for 24 hours to make sure that the temperatures of the pipe energy piles reached a thermal equilibrium. And the thermomechanical characters of energy piles would be accurate. Numerical simulation model is shown in Figure 3.

Nonisothermal laminar flow conjugated with heat transfer is included in the analysis, based on main formulations of continuity, momentum, and energy equations [19, 20].

For calculation of fluid convection inside the pipes, the following equations are used:

$$
\begin{aligned}
\frac{\partial}{\partial t} u+\nabla \cdot(\rho u)= & 0 \\
\rho \frac{\partial}{\partial t} u+\rho u \cdot \nabla u= & -\nabla p+\nabla \\
& \cdot\left\{\mu\left(\nabla u+(\nabla u)^{T}\right)-\frac{2}{3} \mu(\nabla \cdot u) I\right\} \\
& +F,
\end{aligned}
$$

where $\rho$ is density of heat-carrier-fluid, $u$ is the heat-carrierfluid velocity vector, and $F$ is the body force vector. 


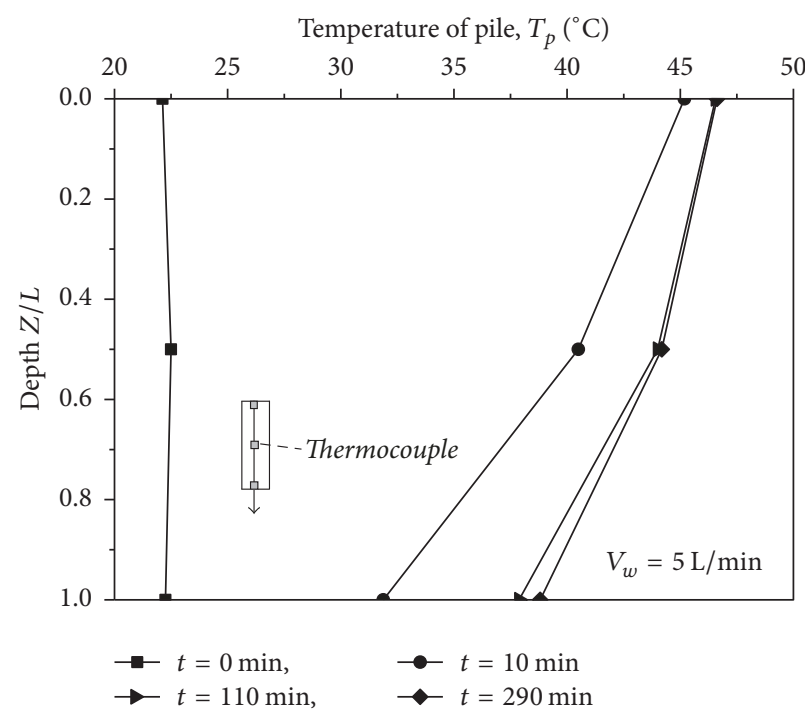

(a)

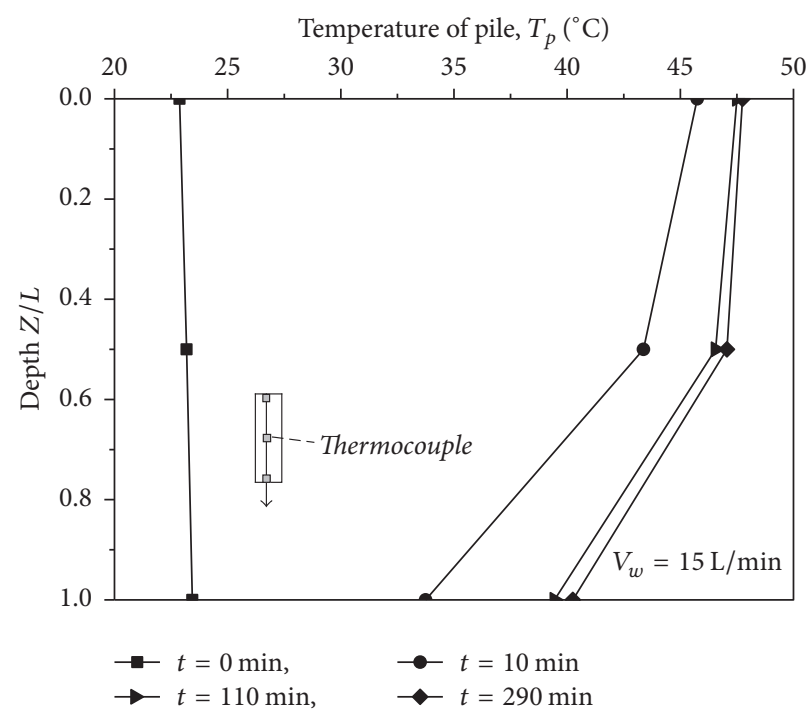

(b)

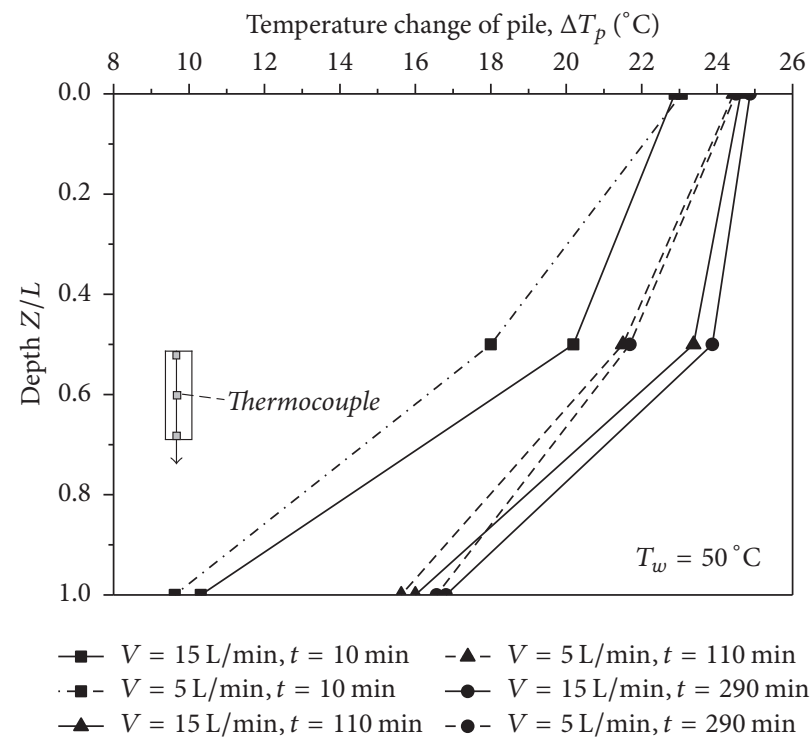

(c)

Figure 2: Temperature profiles of the PCC energy pile without load: (a) Test 5; (b) Test 6; (c) temperature variation in Test 5 and Test 6.

The fluid heat transfer equation is solved as

$$
\begin{aligned}
& \rho C_{p}\left(\frac{\partial T}{\partial t}+u \cdot \nabla T\right)+\nabla \cdot q \\
& =\alpha_{p} T\left(\frac{\partial p}{\partial t}+u \cdot \nabla p\right)+\tau: \nabla u+Q, \\
& \alpha_{p}=-\frac{1}{\rho} \frac{\partial \rho}{\partial T},
\end{aligned}
$$

where $C_{p}$ is the fluid heat capacity at constant pressure, $T$ is the absolute temperature, $\alpha_{p}$ is the coefficient of thermal expansion, $\tau$ is viscous stress tensor, and $Q$ is heat sources other than viscous heating.
The interface supports heat transfer in solid media, for example, pipe walls:

$$
\rho C_{p} \frac{\partial}{\partial t} T=-(\nabla \cdot q)-T \frac{\partial E}{\partial t}+Q
$$

while heat transfer in porous media uses the following (Darcy porous medium):

$$
\begin{aligned}
& \left(\rho C_{p}\right)_{\mathrm{eq}} \frac{\partial T}{\partial t}+\rho C p \cdot u \cdot \nabla T=\nabla \cdot\left(k_{\mathrm{eq}} \nabla T\right)+Q \\
& K_{\mathrm{eq}}=\theta_{p} \cdot k_{p}+\theta_{L} \cdot k \\
& \left(\rho C_{p}\right)_{\mathrm{eq}}=\theta_{p} \cdot \rho_{p} \cdot C_{p, p}+\theta_{L} \cdot \rho \cdot C_{p}, \\
& \theta_{p}+\theta_{L}=1
\end{aligned}
$$




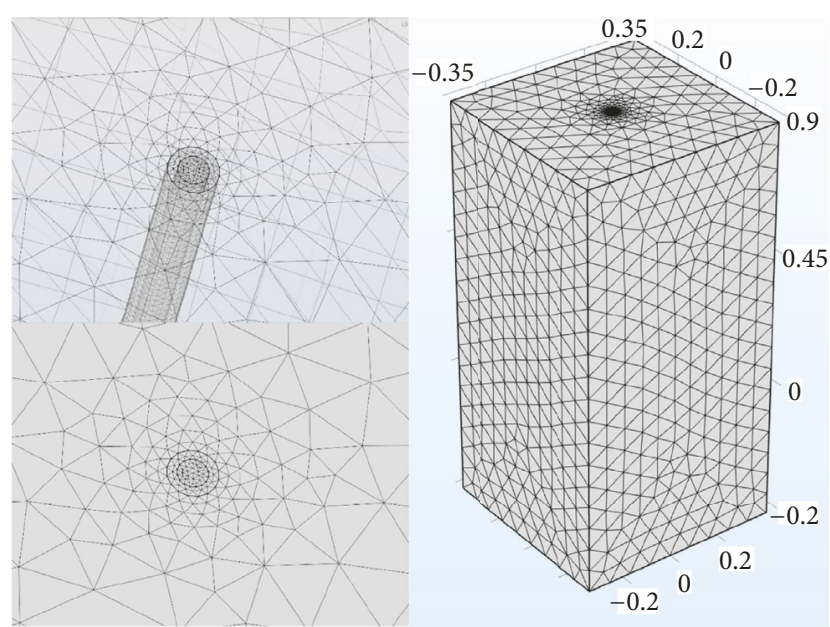

FIGURE 3: Numerical simulation model of energy pile.

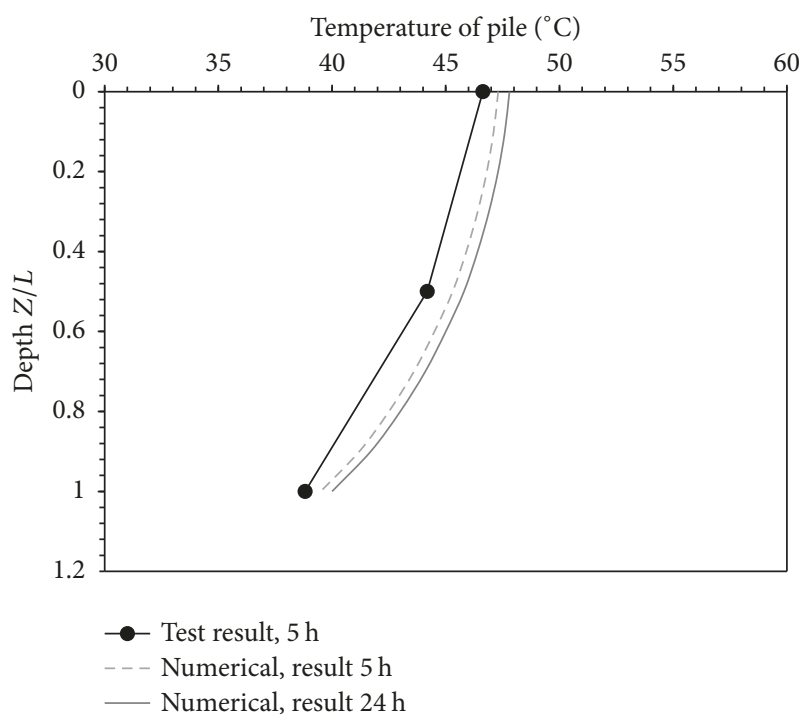

Figure 4: Temperature comparison of numerical result and test value.

where $K_{\mathrm{eq}}$ is equivalent thermal conductivity, $\theta_{p}$ is solid material's volume fraction, $\theta_{L}$ is liquid material's volume fraction in saturated conditions, $\rho_{p}$ is density of solid, $C_{p, p}$ is solid heat capacity, $k_{p}$ is solid thermal conductivity, and $k$ is liquid thermal conductivity.

The numerical results were compared with experimental values in Figure 4. And good agreement was found. And the temperature of pile after heating for 5 hours and 24 hours was also compared. The results show that the average temperature of pile after heating for 5 hours would reach more than $95 \%$ of the average temperature after heating for 24 hours; thus the energy pile has already reached a condition of temperature equilibrium.

Temperature variations of the PEP after heating and cooling were compared with the solid energy pile in Figure 5. The temperature variations after cooling along the PEP were $-6,-7.812$, and $-2.812^{\circ} \mathrm{C}$, respectively. During the

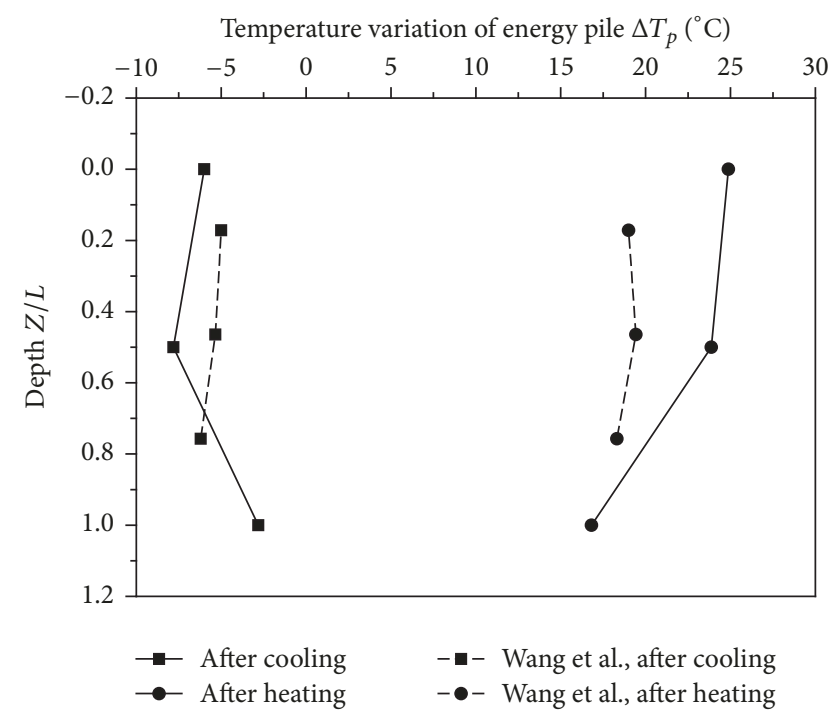

FIgURE 5: Comparison on temperature profiles of the pipe energy pile and solid energy pile.

same period, the temperature variations along solid energy pile were $-5,-5.34$, and $-6.2^{\circ} \mathrm{C}$, respectively. Maximum temperature variations of both piles occurred near the middle part; however, the temperature variation of PEP near the toe dropped rapidly. On the same time, the temperature variations after heating along PEP were 24.875, 23.875, and 16.813 with $19,19.43$, and 18.31 along solid pile, respectively. It can be concluded that the thermal responses of the PEP were slight obviously compared to the solid energy pile. And it can also have some effect on the results of mechanical characters.

5.2. Comparison of Load-Settlement Relationships with Solid Energy Pile. Conventionally, the ultimate shaft resistance along a pile can be estimated by the following:

$$
\tau_{s}=K_{o} \sigma_{\text {vo }}^{\prime} \tan \delta=\left(1-\sin \emptyset^{\prime}\right) \sigma_{\text {vo }}^{\prime} \tan \delta,
$$

where $K_{o}$ is the earth pressure coefficient at rest; $\sigma^{\prime}{ }_{\text {vo }}$ denotes the effective vertical stress; $\emptyset^{\prime}$ is the internal friction angle; and $\delta$ is the friction angle at the pile-soil interface.

The ultimate shaft resistance can also be estimated by the following:

$$
\tau_{s}=\sigma_{\text {ho }}^{\prime} \tan \delta
$$

where $\sigma^{\prime}$ ho is the horizontal stress.

The increase in pile shear stresses during heating can be estimated by the following:

$$
\tau_{s}=\left(\sigma_{\text {ho }}^{\prime}+\Delta \sigma_{\text {ho }}^{\prime}\right) \tan \delta
$$

where $\Delta \sigma^{\prime}$ ho is the increment of effective horizontal stress caused by heating.

The heating caused the pile to be expanded horizontally, which increases the normal stress on the pile-soil interface. The increment of normal stress leads to the increase of shaft 


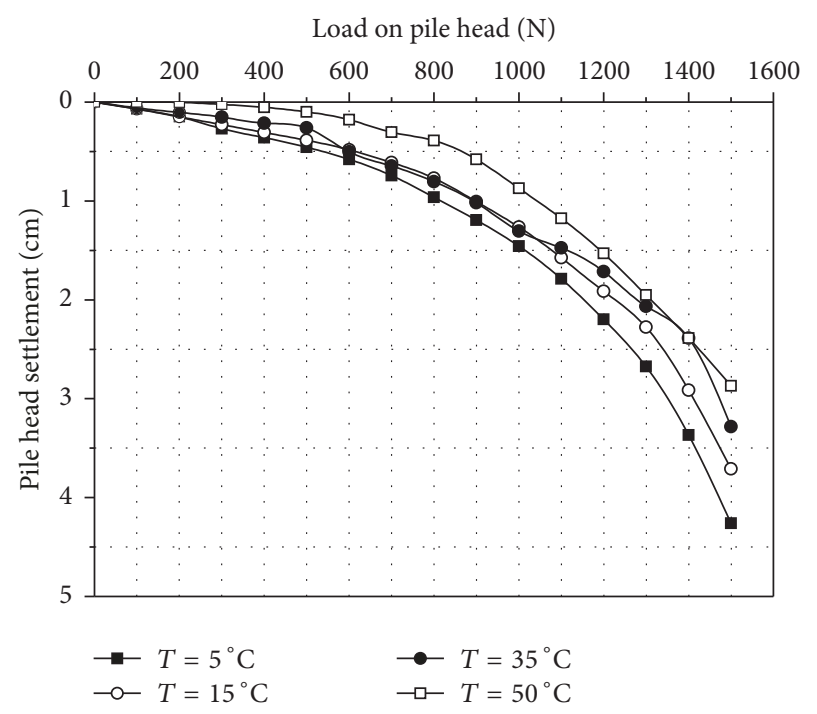

Figure 6: Curves on load-displacement of pile head over time under different heating conditions.

resistance at the pile-soil interface. The horizontal expansion of pile can be estimated using the following:

$$
\Delta a=a_{0} \alpha \Delta T
$$

where $a_{0}$ is the pile radius; $\alpha$ is the expansion coefficient of the material of pile (aluminum in the model test and concrete in the prototype); $\Delta T$ is the temperature increase of energy pile.

According to $\mathrm{Yu}$ [21], the limiting horizontal stress is

$$
\Delta \sigma_{\text {ho }}^{\prime}=\Delta \sigma_{\lim }^{\prime}=\frac{\left(b^{2}-a_{0}{ }^{2}\right)\left(\alpha^{\prime}-1\right)}{\left(1+\alpha^{\prime}\right) b^{2}+\left(\alpha^{\prime}-1\right) a_{0}^{2}} \sigma_{\text {ho }}^{\prime}
$$

where $b$ ( $\approx 15 a_{0}$ in the model test) is the distance between the pile center and model boundary; and $\alpha^{\prime}=\left(1+\sin \emptyset^{\prime}\right) /(1-$ $\left.\sin \emptyset^{\prime}\right)$.

The load-settlement curves in the model tests are shown in Figure 6. When the displacement of pile head reached 1 time of pile diameter $(5 \mathrm{~cm})$, the piles were thought to get into the failure condition. The results show that the bearing capacity increases a little with increasing temperature. When the pile settlement is less than $10 \% D(5 \mathrm{~mm}$ in the model test), all the model piles behaved linearly and the difference of the pile settlements is not significant. After that, higher bearing capacities were measured in the pile under higher temperatures. As mentioned above, when the temperature was raised, the pile would have a radius expansion $\Delta a$ which increases the radial stress between pile-soil interface and thus the increase of shaft resistance. When the temperature of cyclic water in pipe is lower than the ambient temperature (the line " $T=15^{\circ} \mathrm{C}$ "), the radius expansion would convert to radius contraction and $\Delta a$ will be negative. The dropping down of the shaft resistance follows. It can also be observed that, in the final stage, all the settlements have a similar gradient. That is because, with further increment in the axial load, the toe resistance started to take up more applied load; however, the toe resistance would not have a significant increment with the temperature since the sandy soil generally shows a limited affection by temperature changes. As shown in the figure, the results of $50^{\circ} \mathrm{C}$ show evident changes in the bearing capacity. This phenomenon may be caused by the preparation of the sandy soil. The surrounding soil for the test under $50^{\circ} \mathrm{C}$ was thought to have a higher relative density than the other tests.

The comparison of load-settlement profile with Wang et al. [22] was shown in Figure 7. The bearing capacities of the PEP and solid energy pile both decreased with the decreasing temperature. Assume that 20\% of ultimate settlement was inflexion point. The bearing capacity of solid pile in Wang's test decreased by $6 \%$, and bearing capacity of the PEP decreased by $11 \%$ after a $-10^{\circ} \mathrm{C}$ temperature change. Figure 7(b) also shows the effect of increasing temperature on bearing capacity. The bearing capacity of the solid energy pile increased by $13 \%$; during the same period, the bearing capacity of the PEP increased by $17 \%$ with a temperature increment of $35^{\circ} \mathrm{C}$.

As results have shown, the PEP has a similar trend of change in bearing capacity with temperature variation. It is also indicated that bearing capacity of the PEP is likely more sensitive to the temperature variation compared with the traditional solid energy pile. It is partly due to the fact that the mobilized shaft resistance takes most part of the PEP's applied load and the end capacity has a little influence on the total bearing capacity, compared with solid energy pile.

\subsection{Shaft Resistance on Pile-Soil Interface and Axial Strain.} The pile placed in the ground could not expand (or contract) freely, owing to the shaft resistance between pile-soil interface and any end restraint. The measured axial strain $\varepsilon_{T \text {-Obs }}$ caused by temperature changes will be different from the pile which could expand freely. The restrained axial strain $\varepsilon_{T \text {-Rstr }}$ will be created for the pile in the ground, and it could be determined as follows [23]:

$$
\varepsilon_{T \text {-Rstr }}=\varepsilon_{T \text {-Free }}-\varepsilon_{T \text {-Obs }} .
$$

The restrained strain will also induce thermal stress in the pile, and the thermal stress is determined as follows:

$$
\sigma_{T-\mathrm{Rstr}}=E\left(\varepsilon_{T-\mathrm{Obs}}-\alpha_{C} \Delta T\right) .
$$

The pile-soil displacement induced by temperature change will mobilize shaft resistance at the pile-soil interface. The mobilized shaft resistance $f_{s-s, \text { mob,j }}$ for solid pile could be determined as follows:

$$
f_{s-s, \mathrm{mob}, j}=\frac{\left(\sigma_{T-\mathrm{Rstr}, j}-\sigma_{T-\mathrm{Rstr}, j-1}\right) D}{4 \Delta l} .
$$

The toe of energy pipe pile in this test was sealed, and the mobilized shear stress $f_{s-p, \text { mob,j }}$ for the energy pipe pile could be determined as follows:

$$
f_{s-p, \text { mob }, j}=\frac{\left(\sigma_{T-\mathrm{Rstr}, j}-\sigma_{T-\mathrm{Rstr}, j-1}\right)\left(D_{\mathrm{out}}^{2}-D_{\text {in }}^{2}\right)}{4 D_{\mathrm{out}} \Delta l} .
$$

Figure 8 shows the mobilized shaft resistance of the PEP. When only mechanical load (working load $900 \mathrm{~N}$ ) 


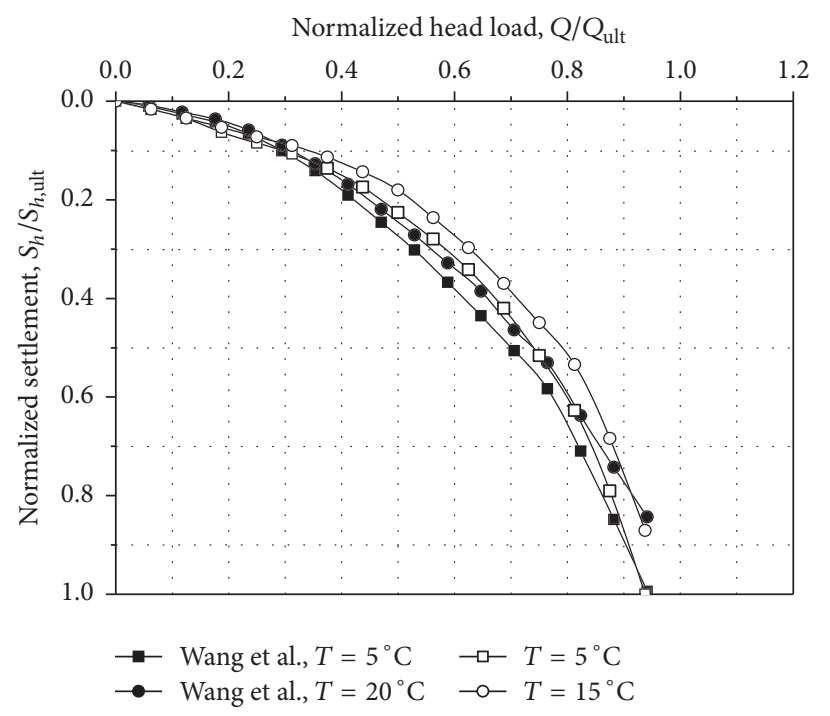

(a)

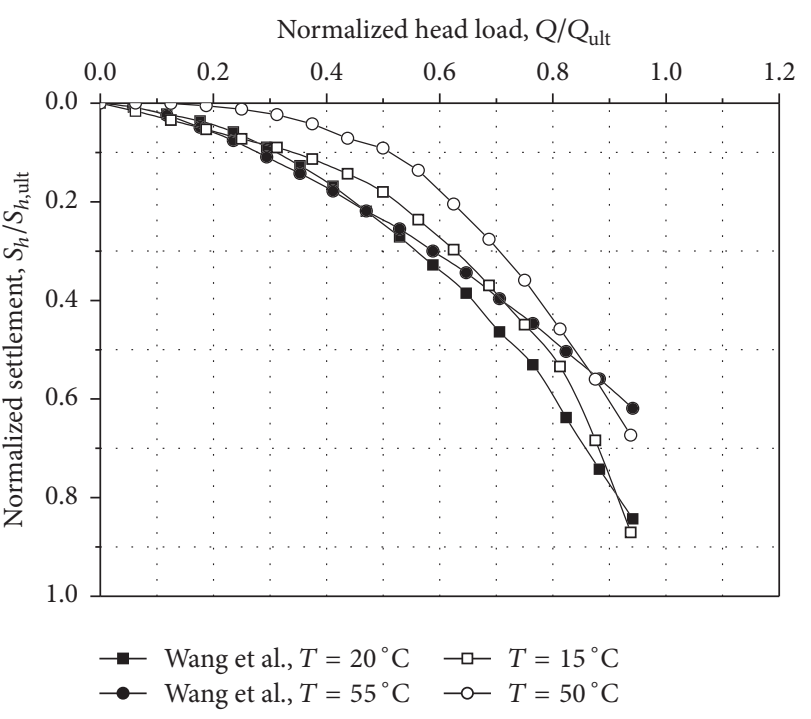

(b)

Figure 7: Comparison on normalized pile head settlement with the solid energy pile: (a) cooling; (b) heating.

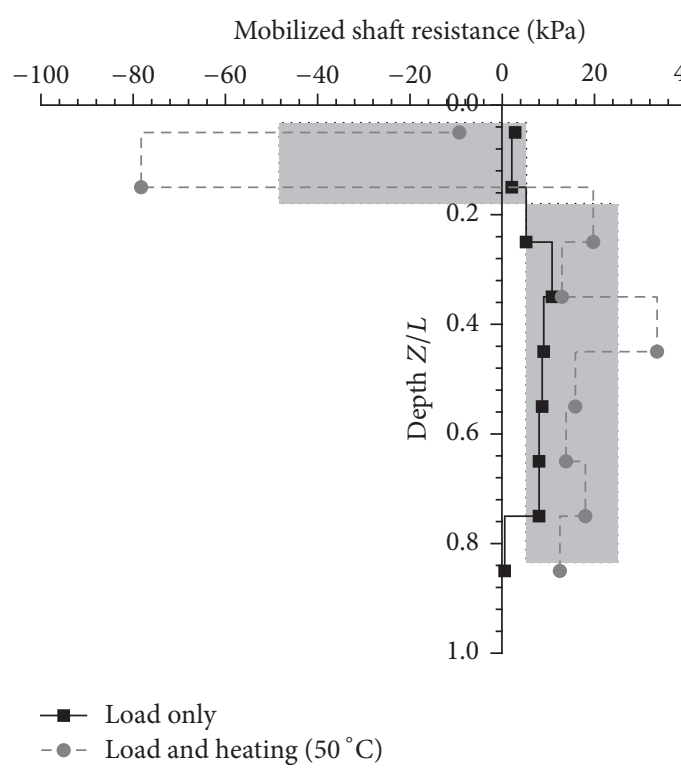

(a)

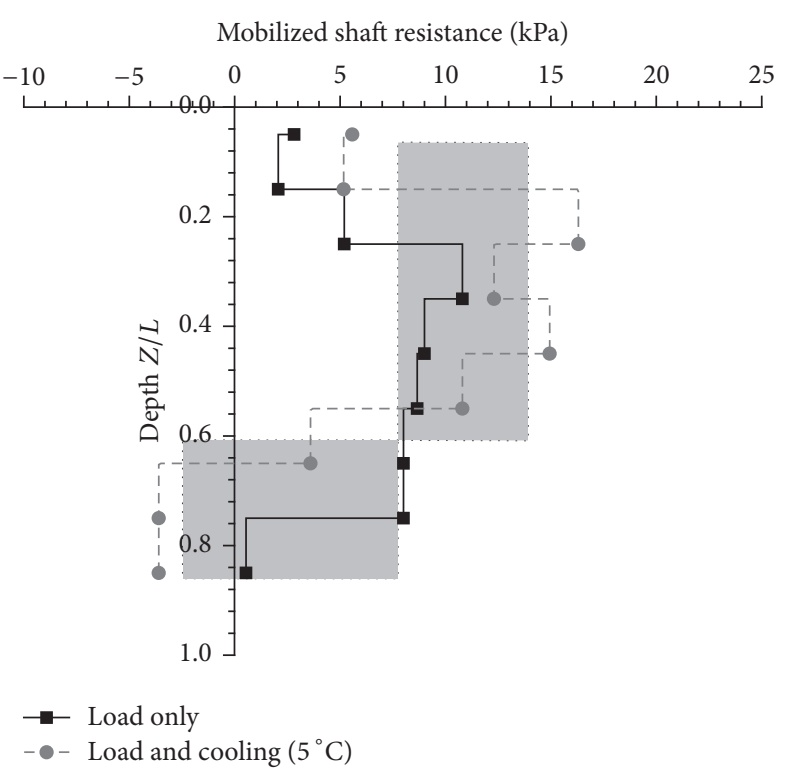

(b)

FIGURE 8: Mobilized shaft resistance distribution along the PEP under different temperatures: (a) heating; (b) cooling.

was applied, the maximum shaft resistance was $10.8 \mathrm{kPa}$, which occurred in depth of $0.35 \mathrm{~m}$, and the minimum shaft resistance was $0.54 \mathrm{kPa}$ near the pile toe. The shaft resistance along the pile did not change evidently; meanwhile, it was also not a constant as shown in Figure 8(a) (Bourne-Webb et al., 2013). The soil near pile toe and the loading on the pile top both have a restraint to the displacement between pilesoil interfaces, which is different with the freely expanding (contract) solid pile.

After heating, the shaft resistance near pile top changed to negative which means it was downwards. The maximum value of negative shaft resistance was $-78.28 \mathrm{kPa}$. And the shaft stress under depth of $0.25 \mathrm{~m}$ was positive and larger than that with mechanical load only. The maximum and minimum positive shaft stress were $19.75 \mathrm{kPa}$ and $12.54 \mathrm{kPa}$, respectively. The shaded area in Figure 6 represents change due to heating. As shown in Figures 8(a) and 9(a), the shaft stress of the PEP under heating and loading has a similar trend with the solid pile. Since the model PEP was made by aluminum, its thermal expansion was large compared to that made by concrete and the negative shaft stress near the top part was more obvious than the concrete solid pile in Bourne-Webb et al.'s test.

The comparison of shear stress under mechanical load only and cooling load was also shown in Figure $8(\mathrm{~b})$. The 


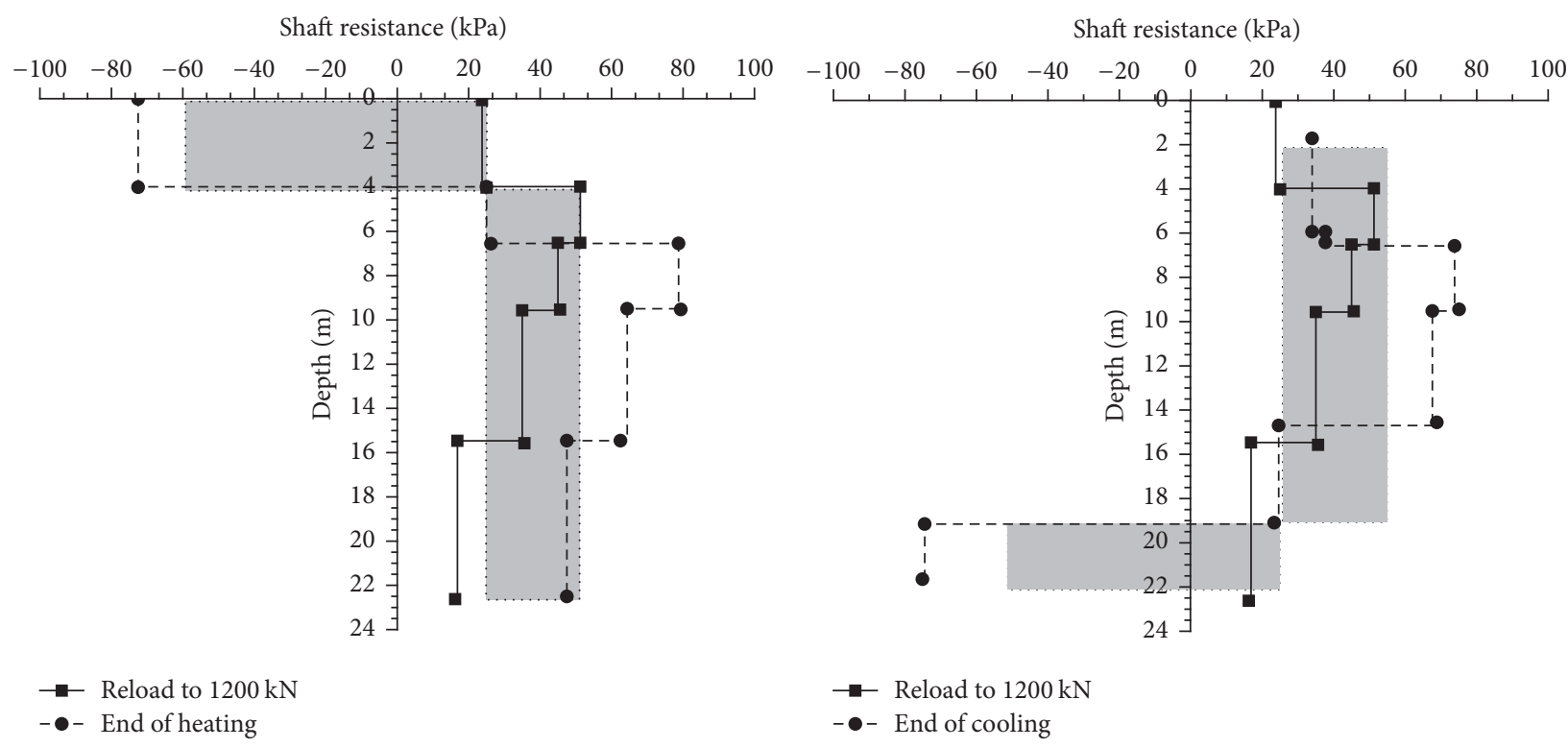

(a)

(b)

FIGURE 9: Shaft resistance distribution of the solid energy pile (Bourne-Webb et al., 2013): (a) heating; (b) cooling.

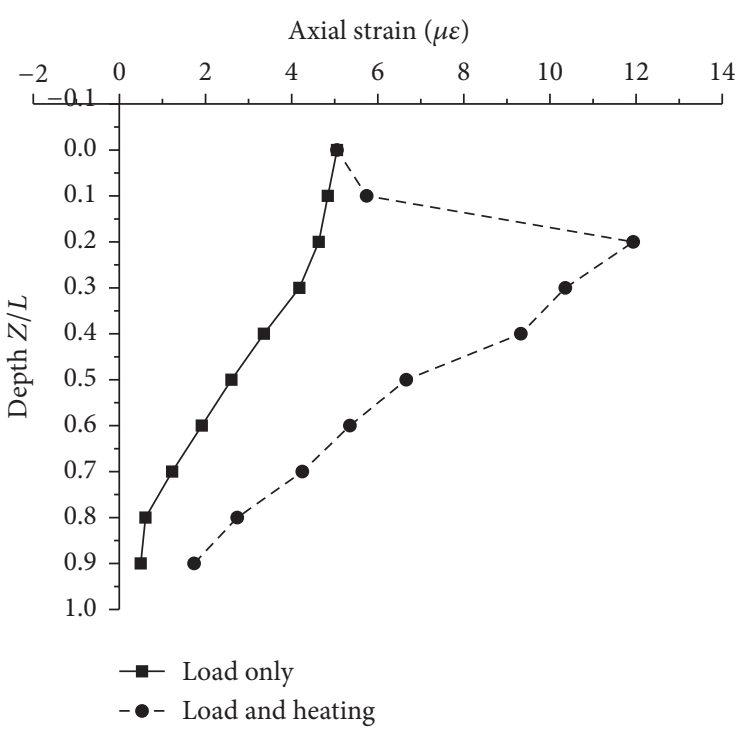

(a)

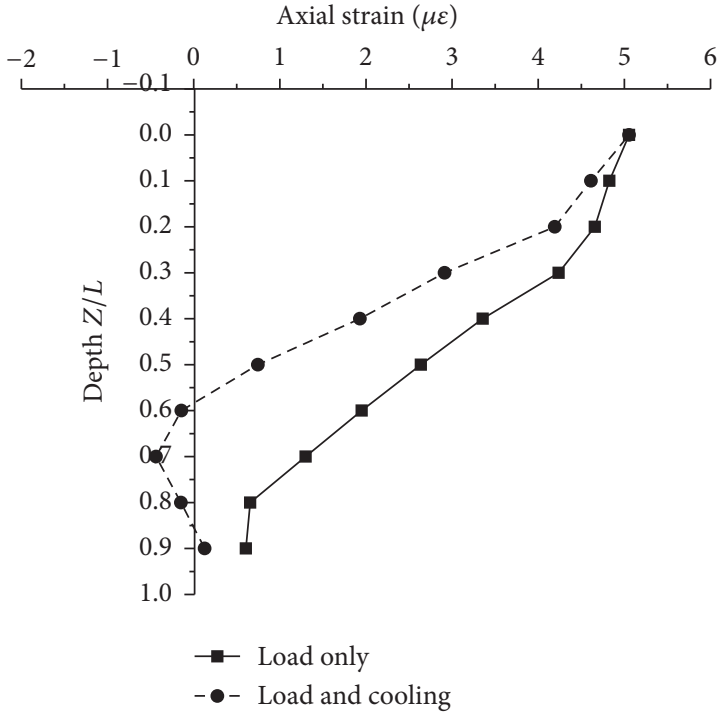

(b)

FIgURE 10: Axial strain distribution of the PEP: (a) heating; (b) cooling.

maximum shear stress and minimum shear stress were $16.3 \mathrm{kPa}$ and $-3.6 \mathrm{kPa}$, respectively. After cooling, the mobilized shear stress in the upper part of pile shows an increase relative to that under mechanical load only and reverses in the lower part of pile (from upwards to downwards). When the pile was cooled and contracted, the soil under pile and load part on the head of pile would not have an evident restraint to the pile. The shaded area shows the cooling effect on shaft stress, and it also shows a similar trend compared with the solid pile as shown in Figure 9(b).

The axial strain distribution is also shown in Figure 10. When only mechanical load was applied to the pile, the axial strain decreased with depth because the shaft resistance led to the decreasing of axial load. After heating, the axial strain increased along the pile depth, while after cooling, the axial strain decreased along the pile and the direction of axial strain even changed at the toe part of pile.

\subsection{Displacement of Pile Head under Long-Term Thermal} Effects. Figure 11 shows the displacement of pile head under a heating-cooling cycle. The pile head would heave when the pile was heated. However, after heating, the pile head would settle until the temperature of pile decreased to the room temperature. At the end of the process, the settlement of pile 


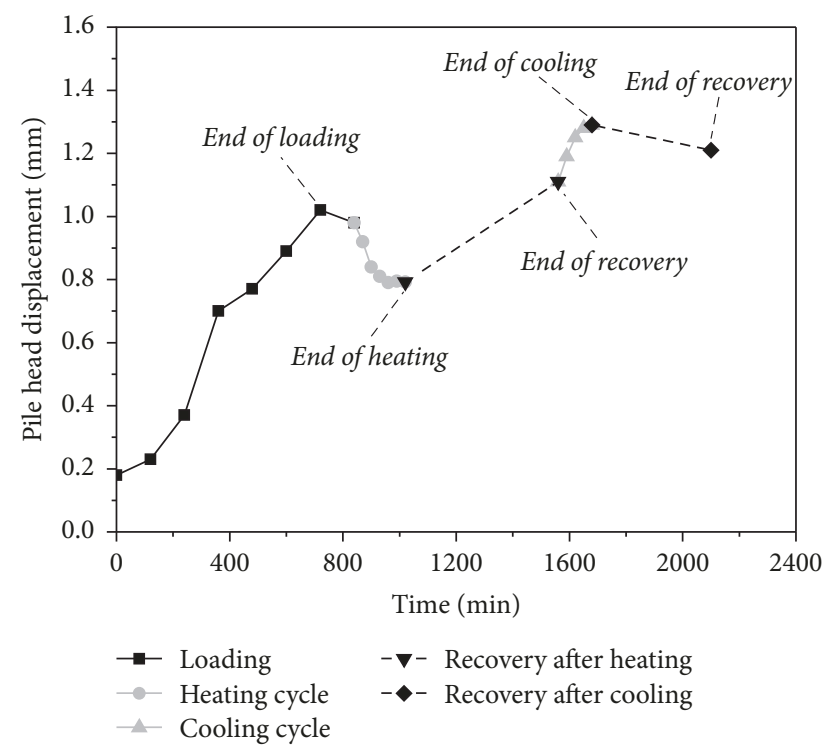

FIGURE 11: The pile head displacement under a heating-cooling cycle.

head is more than the heave displacement, which means that uncovered plastic displacement was created along the pile. The pile head would settle for the constriction of pile under decreasing temperature. When the temperature recovered, the displacements of the pile head would not return to the initial value. Plastic deformation also occurred along the pile in this period. The plastic deformation is likely caused by the contraction of soil may during the thermal cycles with temperature variation, which need to be studied further in the future.

\section{Conclusions}

In this study, load tests on four instrumented aluminum model piles were carried out to investigate thermal effects on the settlement patterns and capacities of single piles in saturated sand. Based on this study, the following conclusions can be drawn:

(1) With the increasing velocity of cyclic water, the static temperature of pile would also be higher. On the same time, after cooling or heating, the temperature variations of the PEP are larger than the solid energy pile.

(2) The bearing capacity of pipe energy pile showed similar trend with the solid energy pile under different temperature variation. It increased with the increasing temperature of cyclic water and decreased when the PEP was cooling by cyclic water. The PEPs behaved softer (bearing capacity decreased by $11 \%$ ) after being cooled than the solid energy pile (bearing capacity decreased by $6 \%$ ). On the same time, the bearing capacity of the PEP increased $17 \%$ with temperature increment of $35^{\circ} \mathrm{C}$, which is more than the solid energy pile with $13 \%$ during the same period. It is indicated that PEPs seem to be more sensitive to the temperature variation than the solid energy pile.
(3) The shaft resistance along pile-soil interface was calculated and compared with the solid energy pile. The direction of the shaft resistance near the top part of pile converted after heating because of the upward displacement of pile head, and the shaft resistance under $0.25 \mathrm{~m}$ was positive and larger than the shaft resistance under load only. After cooling, the shaft resistance near top part increased with the contraction of the pile and then converted to negative near the toe of the pile. The mobilized shaft resistance profile is similar to the solid pile without restraints at both ends.

(4) During the full heating-cooling cycle, pile head heaved with increasing temperature and the upward displacements would decrease after heating. However, when the temperature recovers to the room temperature, there are still some unrecoverable displacements because the thermal expansion of pile toe inside the sand led to plastic deformation of the sand. On the following cooling period, the pile head displacements were downward because of the contraction under cooling. After recovering to the room temperature, plastic displacements were also observed due to the contraction of sand.

\section{Conflicts of Interest}

The authors declare that they have no conflicts of interest.

\section{Acknowledgments}

The author would like to acknowledge the National Natural Science Foundation of China (Grant no. 51378178) and the Research Innovation Program for College Graduates of Jiangsu Province (Grant no. KYZZ15_0145), which collectively funded this project.

\section{References}

[1] S. Kavanaugh, k. Rafferty, and M. Geshwiler, "Ground-source heat pumps-design of geothermal systems for commercial and industrial buildings," ASHRAE, article 167, 1997.

[2] P. Hughes, "Geothermal (Ground-Source)Heat Pumps: Market Status, Barriers to Adoption, and Actions to Overcome Barriers," Oak Ridge Nat. Lab. Report ORNL-2008/232, 2008.

[3] B. Saner, "Shallow geothermal energy," GHC Bulletin, vol. 22, no. 4, pp. 19-25, 2001.

[4] J. G. Agar, N. R. Morgenstern, and J. D. Scott, "Thermal expansion and pore pressure generation in oil sands.," Canadian Geotechnical Journal, vol. 23, no. 3, pp. 327-333, 1986.

[5] J. G. Agar, N. R. Morgenstern, and J. D. Scott, "Shear strength and stress-strain behaviour of Athabasca oil sand at elevated temperatures and pressures," Canadian Geotechnical Journal, vol. 24, no. 1, pp. 1-10, 1987.

[6] C. G. Olgun, T. Y. Ozudogru, and C. F. Arson, "Thermomechanical radial expansion of heat exchanger piles and possible effects on contact pressures at pile-soil interface," Geotechnique Letters, vol. 4, pp. 170-178, 2014. 
[7] C. W. W. Ng, C. Shi, A. Gunawan, L. Laloui, and H. L. Liu, "Centrifuge modelling of heating effects on energy pile performance in saturated sand," Canadian Geotechnical Journal, vol. 52, no. 8, pp. 1-13, 2015.

[8] J. C. Goode and J. S. McCartney, "Centrifuge modeling of endrestraint effects in energy foundations," Journal of Geotechnical and Geoenvironmental Engineering, vol. 141, no. 8, article 04015034, 2015.

[9] L. Laloui, M. Moreni, and L. Vulliet, "Comportement d'un pieu bi-fonction, fondation et échangeur de chaleur," Canadian Geotechnical Journal, vol. 40, no. 2, pp. 388-402, 2003.

[10] L. Laloui, M. Nuth, and L. Vulliet, "Experimental and numerical investigations of the behaviour of a heat exchanger pile," International Journal for Numerical and Analytical Methods in Geomechanics, vol. 30, no. 8, pp. 763-781, 2006.

[11] P. J. Bourne-Webb, B. Amatya, K. Soga, T. Amis, C. Davidson, and P. Payne, "Energy pile test at lambeth college, London: geotechnical and thermodynamic aspects of pile response to heat cycles," Geotechnique, vol. 59, no. 3, pp. 237-248, 2009.

[12] K. D. Murphy, J. S. McCartney, and K. S. Henry, "Evaluation of thermo-mechanical and thermal behavior of full-scale energy foundations," Acta Geotechnica, vol. 10, no. 2, pp. 179-195, 2015.

[13] K. D. Murphy and J. S. McCartney, "Seasonal response of energy foundations during building operation," Geotechnical and Geological Engineering, vol. 33, no. 2, pp. 1-14, 2015.

[14] B. L. Amatya, K. Soga, P. J. Bourne-Webb, T. Amis, and L. Laloui, "Thermo-mechanical behaviour of energy piles," Geotechnique, vol. 62, no. 6, pp. 503-519, 2012.

[15] J. S. McCartney, "Engineering performance of energy foundations," in Proceedings of the 14th Pan-American Conference on Soil Mechanics and Geotechnical Engineering, Canadian Geotechnical Society, Ottawa, Canada, 2011.

[16] J. S. McCartney and J. E. Rosenberg, "Impact of heat exchange on side shear in thermo-active foundations," in Proceedings of the Geo-Frontiers 2011: Advances in Geotechnical Engineering, J. Han and D. E. Alzamora, Eds., pp. 488-498, Reston, VA, USA, March 2011.

[17] K. D. Murphy, J. S. McCartney, and H. K. Henry, "Thermomechanical characterization of a full-scale energy foundation," in From Soil Behavior Fundamentals to Innovations in Geotechnical Engineering: Honoring Roy E. Olson, M. Iskander, J. E. Garlanger, and M. H. Hussein, Eds., pp. 617-628, American Society of Civil Engineers, Reston, VA, USA, 2014.

[18] M. A. Stewart and J. S. McCartney, "Centrifuge modeling of soil-structure interaction in energy foundations," Journal of Geotechnical and Geoenvironmental Engineering, vol. 140, no. 4, article 04013044, 2014.

[19] J. C. Goode, M. Zhang, and J. S. McCartney, "Centrifuge modelling of energy foundations in sand," in Proceedings of the 8th International Conference on Physical Modelling in Geotechnics 2014 (ICPMG2014), pp. 729-736, CRC Press, Perth, Australia, 2014.

[20] V. Fioravante, "On the shaft friction modelling of nondisplacement piles in sand," Soils and Foundations, vol. 42, no. 2, pp. 23-33, 2002.

[21] H. Yu, Cavity Expansion Methods in Geomechanics, Springer, Dordrecht, Netherlands, 2000.

[22] C. L. Wang, H. L. Liu, G. Q. Kong, C. W. W. Ng, and Wu. Di, "Model tests of energy piles with and without vertical load," Geotechnical Engineering, vol. 3, no. 4, pp. 203-213, 2016.
[23] P. J. Bourne-Webb, B. Amatya, and K. Soga, "A framework for understanding energy pile behaviour," Geotechnical Engineering, vol. 166, no. 2, pp. 170-177, 2013. 


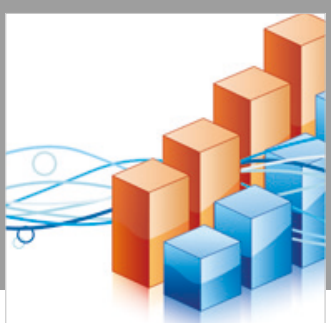

Advances in

Operations Research

\section{-n-m}
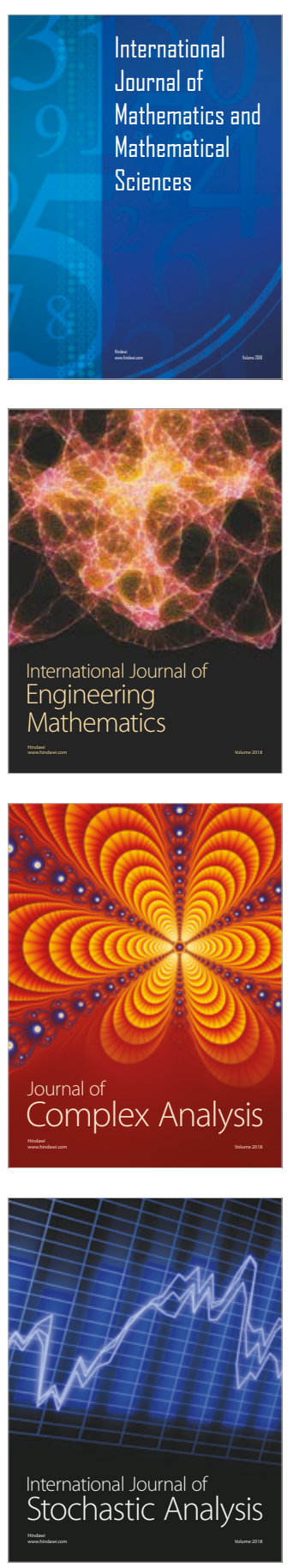
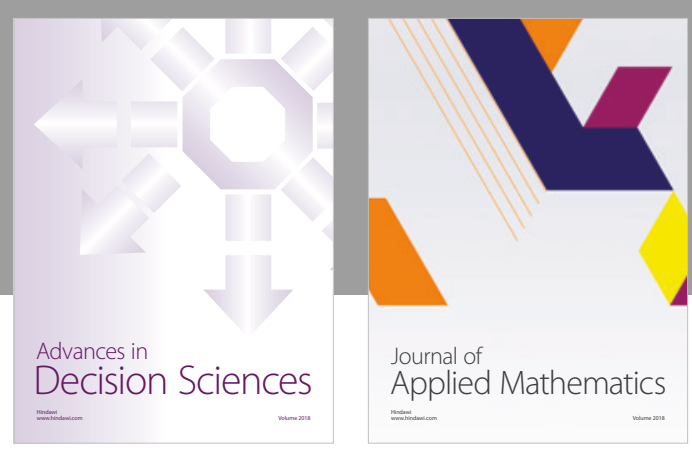

Journal of

Applied Mathematics
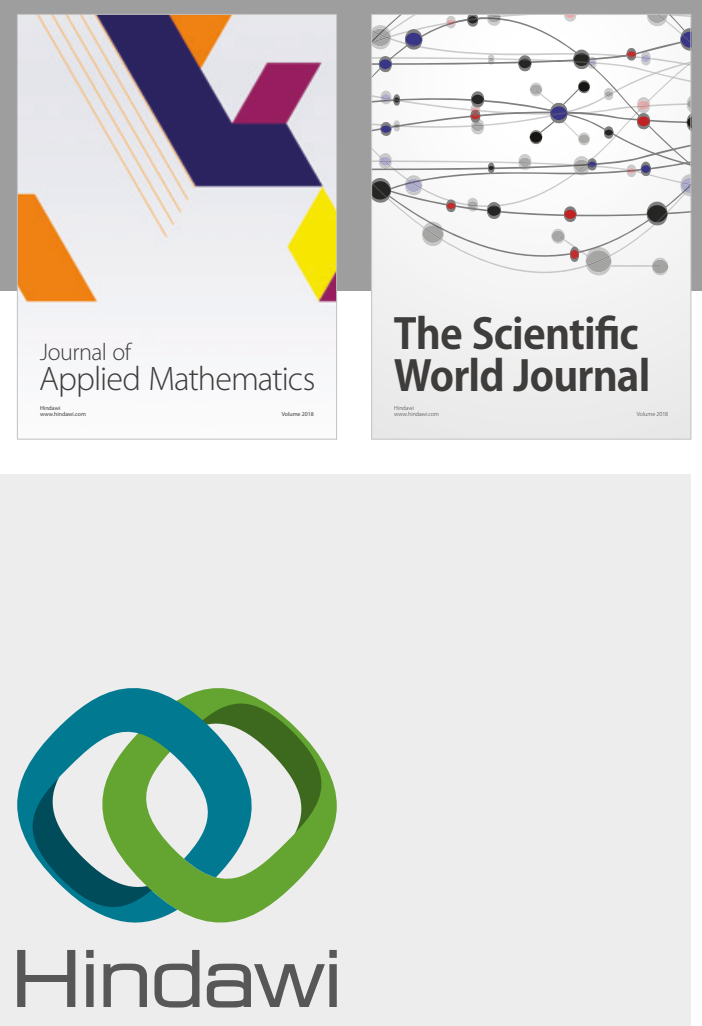

Submit your manuscripts at

www.hindawi.com

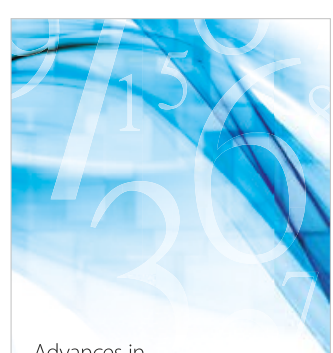

Advances in
Numerical Analysis
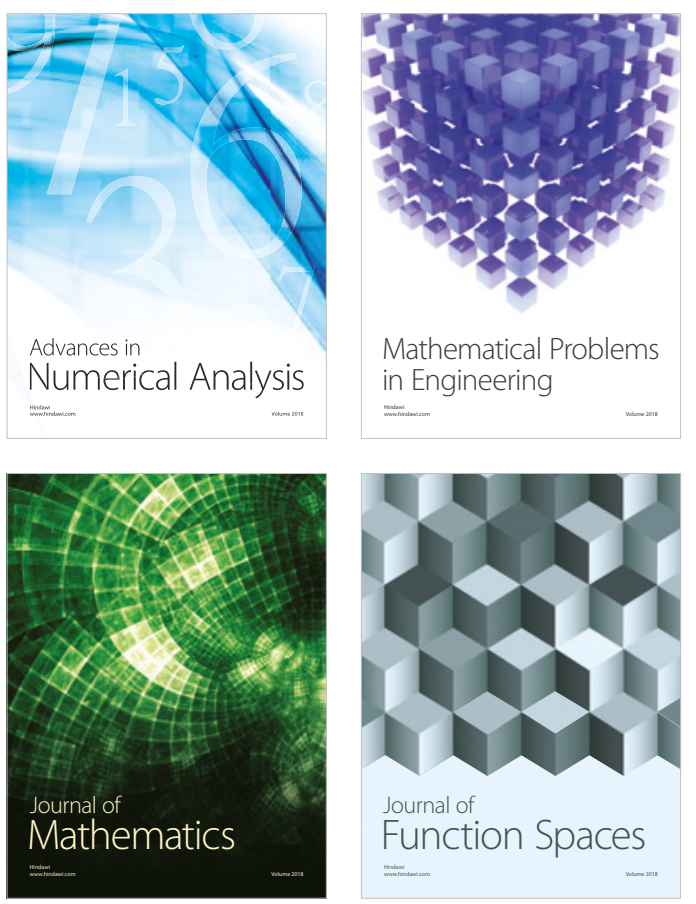

Mathematical Problems in Engineering

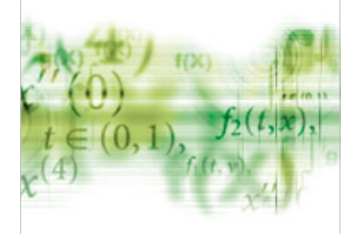

International Journal of

Differential Equations

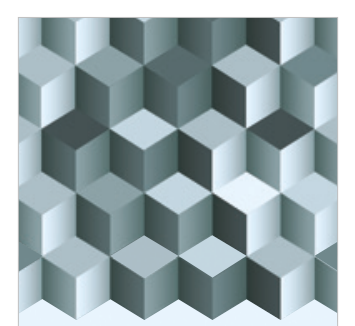

Journal of

Function Spaces

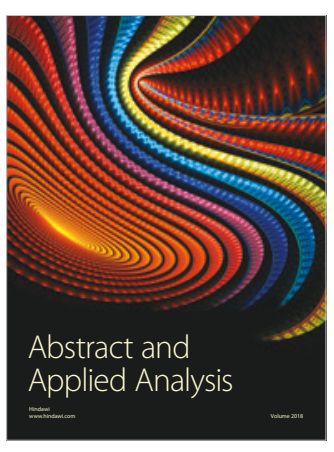

The Scientific

World Journal

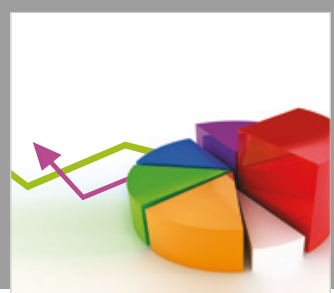

Journal of

Probability and Statistics
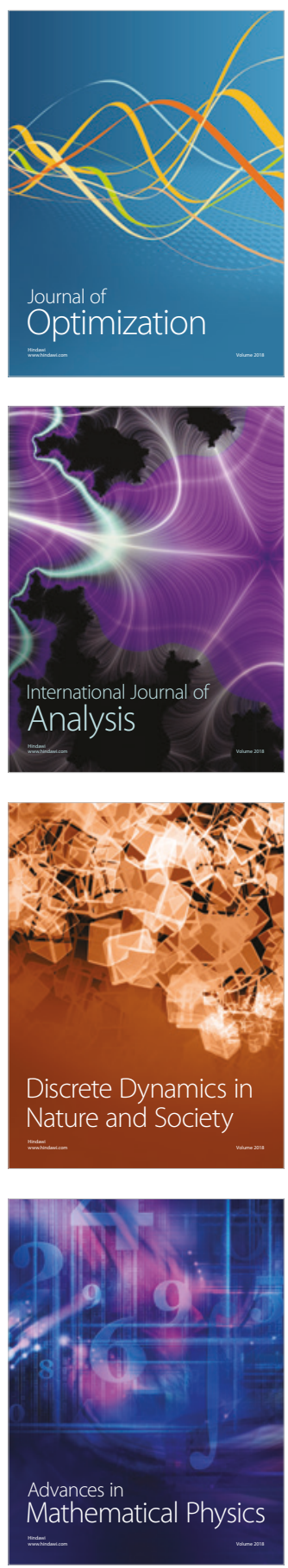